\title{
MONTALVO Y MENÉNDEZ PELAYO
}

Ni el paralelo forzado ni la imaginable discordia: simplemente las mutuas "simpatías y diferencias" a través de la correspondencia personal entre ambos escritores". Un epistolario en parte inédito ofrece no pocas sorpresas; más cuando lo conocido anda disperso y fragmentado, invitando ya a la parcialidad. Las cartas de Menéndez Pelayo se han publicado íntegras, pero apenas se utilizan para entresacar los elogios a Montalvo, y de las tres de éste se conoce una, mutilada y anotada tan apresuradamente que no lo favorece 2 . Valga lo uno por lo otro; pero no se ha puesto mucho en claro, y todo amenaza ponerse peor si con el material reunido dejamos de llevar las cosas a su dueño.

' Las cartas autógrafas de Montalvo se conservan en la Biblioteca de Menéndez Pelayo, de Santander: 1) de "Madrid, junio 3 de 1883 "; 2) de "París, junio 24 de 1887 "; y 3) de "París, julio 7 de 1887 ". Esta última ha sido publicada parcialmente por el director de la Biblioteca, Enrigue SÁnchez REyes, en su recopilación Menéndez Pelayo y la hispanidad. Correspondencia entre Menendez Pelayo y escritores hispano-americanos, BBMP, 27 (1951), 250-252. Las cartas autógrafas de Menéndez Pelayo se guardan en la Casa de Montalvo, de Ambato: I) de "Madrid, 3 de julio de 1887 "; y 2) de "Santander, 18 de setiembre de 1887 ". Don Carlos Bolívar Sevilla, director de la Casa de Montalvo, nos ha enviado copia mecanográfica de ambas; don Antonio JAÉn MORENTE las ha publicado en su trabajo sobre Juan Montalyo y Emilia Pardo y Bazán, Quito, 1944, pp. 68-72. Agradecemos aquí a los compiladores y directores de las instituciones respectivas el obsequio de sus trabajos y la autorización para utilizar lo publicado y lo inédito, lo mismo a don Isaac J. Barrera que, por encargo de nuestro amigo el filólogo ecuatoriano don Humberto Toscano, nos envió también copia mecanográfica de las dos cartas de Menéndez Pelayo.

" Oscar EFrÉn Reyes, en su excelente Vida de Juan Montalvo (Quito, 1935), publica, altera y mezcla bajo unas mismas comillas los fragmentos elogiosos de las dos cartas, sin indicar fecha ni procedencia (cf. la $2^{3}$ ed., Quito, 1943, pp. 227-228). Darío Guevara, en su "biografía novelada de Juan Montalvo o el Cervantes de América", fragmenta y altera unos renglones de la segunda carta, citando el trabajo de Jaén Morente (Quijote y maestro, Quito, 1947, pp. 225 y 280). JaÉn Morente, op. cit., subraya los elogios a Montalvo y al Ecuador (pp. 66 y 68), pasa como sobre ascuas al hablar de la "cuestión relativa a una agresión literaria y aun personal contra don Marcelino" (p. 67) y ofrece algunos defectos de trascripción que aquí se corrigen sin indicarlo (Pp. 68 y 7 ). IsaAC J. Barrera, al contestar públicamente ciertas consultas nuestras, aprovecha lo elogioso y augura retrospectivamente que "Montalvo 
Montalvo llega la tercera vez a París por octubre de 1881 , dejando pendiente en Panamá la publicación seriada de las Catilinarias; la duodécima y última apareció allá el primero de enero del nuevo año. Dedica todo 1882 y parte de 1889 a la edición de los Siete tratados; por mayo de ese año salieron los primeros ejemplares. Bien provisto de ellos haría el viaje a Madrid, sugerido, según se dice, por doña Emilia Pardo Bazán y otros amigos españoles. Campoamor, Castelar, Núñez de Arce, Valera y algunos más pedirían su incorporación a la Academia ${ }^{3}$. Montalvo debió de presentarse en la villa y corte a fines de mayo de $1883^{4}$.

A principios de junio escribió su primera carta a Menéndez Pelayo y le envió los Siete tratados con respetuosa dedicatoria; quizá Montalvo, aconsejado por sus amigos académicos, trataba de ganar su benevolencia para la votación de rigor:

Sor. don Marcelino Menéndez Pelayo.

Madrid, junio 3 de 1883 .

Muy señor mío:

La fama le ha servido á $U$. con muy buena voluntad; tan joven como es, ya es $U$. conocido en dondequiera que se habla la lengua Castellana; ni podía por ménos un ingenio así tan precoz y laborioso.

Como prueba de estimación remito á U. un ejemplar de la obra que acabo de dar á luz en Francia". Por lo que sé de U., no

debió replicarle indignado" a Menéndez Pelayo (cf. su "Montalvo y Menéndez Pelayo", en El Comercio, Quito, in de noviembre de 1952). Finalmente, la nota que encabeza la carta de Montalvo publicada en el $B B M P$, además de referir inexactitudes sobre la vida y obra de Montalvo, inserta estos renglones: "esta misteriosa y larga carta (va muy abreviada), carta en que se habla de alguna polémica o diatriba contra Menéndez Pelayo, que no he podido poner en claro". La letra cursiva y el paréntesis no son nuestros.

"Cf. ReYss, op. cit., pp. 378 y $380-382$.

4 Aunque los biógrafos Reyes y Guevara (opp. cit., pp. 379 y $38_{5}$, y p. $19^{6}$, respectivamente) están acordes en fechar la llegada de Montalvo a Madrid en junio, la data de la primera carta a Menéndez Pelayo y la dedicatoria del ejemplar de los Siete tratados que conserva la Academia ("Al Exmo. Señor don Manuel Tamayo y Baus, el autor, con el más profundo respeto. Juan Montalvo. Madrid, á $1^{\circ}$ de Junio de $1889^{\prime \prime}$ ) nos lanza a esta suposición; por lo menos, estamos seguros de que no "emprendió su viaje a España" en junio, ya que el $1^{\circ}$ de ese mes firmaba en Madrid.

Siete Tratados / por / Juan Montalvo / Tomo primero / Besanzon / Imprenta de José Jacquin / 1882; 400 pp. más 415 del Tomo segundo, que tiene las mismas características. El tomo primero lleva esta dedicatoria autógrafa: "Al señor Menéndez Pelayo, Homenaje del autor, Juan Montalvo. Madrid junio 3 de $1883^{\prime \prime}$ (signaturas 4298 y 4299 de la Biblioteca de Menéndez Pelayo, Santander). En los dias en que Montalvo firmó las dedicatorias para Tamayo y Baus y Menéndez Pelayo, debió de enviar también sus Siete tratados a Juan Valera; así lo hizo saber éste, desde Lisboa, a Menéndez Pelayo en carta fechada el 7 de junio de 1883 : “¿Quién es y qué piensa usted del ameri- 
Montalvo llega la tercera vez a París por octubre de 1881 , dejando pendiente en Panamá la publicación seriada de las Catilinarias; la duodécima y última apareció allá el primero de enero del nuevo año. Dedica todo 1882 y parte de 1883 a la edición de los Siete tratados; por mayo de ese año salieron los primeros ejemplares. Bien provisto de ellos haría el viaje a Madrid, sugerido, según se dice, por doña Emilia Pardo Bazán y otros amigos españoles. Campoamor, Castelar, Núñez de Arce, Valera y algunos más pedirían su incorporación a la Academia ${ }^{3}$. Montalvo debió de presentarse en la villa y corte a fines de mayo de $1883^{4}$.

A principios de junio escribió su primera carta a Menéndez Pelayo y le envió los Siete tratados con respetuosa dedicatoria; quizá Montalvo, aconsejado por sus amigos académicos, trataba de ganar su benevolencia para la votación de rigor:

Sor. don Marcelino Menéndez Pelayo.

Madrid, junio 3 de $188_{3}$.

Muy señor mío:

La fama le ha servido á $U$. con muy buena voluntad; tan joven como es, ya es U. conocido en dondequiera que se habla la lengua Castellana; ni podía por ménos un ingenio así tan precoz y laborioso.

Como prueba de estimación remito á $\mathbf{U}$. un ejemplar de la obra que acabo de dar á luz en Francia”. Por lo que sé de U., no

debió replicarle indignado" a Menéndez Pelayo (cf. su "Montalvo y Menéndez Pelayo", en El Comercio, Quito, 11 de noviembre de 1952). Finalmente, la nota que encabeza la carta de Montalvo publicada en el $\boldsymbol{B B} \boldsymbol{M}$, además de referir inexactitudes sobre la vida y obra de Montalvo, inserta estos renglones: "esta misteriosa y larga carta (va muy abreviada), carta en que se habla de alguna polémica o diatriba contra Menéndez Pelayo, que no he podido poner en claro". La letra cursiva y el paréntesis no son nuestros.

"Cf. Reyes, op. cit., pp. 378 y $380-382$.

4 Aunque los biógrafos Reyes y Guevara (opp. cit., pp. 379 y 385 , y p. 196 , respectivamente) están acordes en fechar la llegada de Montalvo a Madrid en junio, la data de la primera carta a Menéndez Pelayo y la dedicatoria del ejemplar de los Siete tratados que conserva la Academia ("Al Exmo. Señor don Manuel Tamayo y Baus, el autor, con el más profundo respeto. Juan Montalwo. Madrid, á $1^{\circ}$ de Junio de $1883^{\prime \prime)}$ nos lanza a esta suposición; por lo menos, estamos seguros de que no "emprendió su viaje a España" en junio, ya que el $1^{\circ}$ de ese mes firmaba en Madrid.

s Siete Tratados / por / Juan Montalvo / Tomo primero / Besanzon / Imprenta de José Jacquin / 1882; 4 oo pp. más $4^{15}$ del Tomo segundo, que tiene las mismas características. El tomo primero lleva esta dedicatoria autógrafa: "Al señor Menéndez Pelayo, Homenaje del autor, Juan Montalvo. Madrid junio 3 de $1883^{\prime \prime}$ (signaturas 4298 y 4299 de la Biblioteca de Menéndez Pelayo, Santander). En los días en que Montalvo firmó las dedicatorias para Tamayo y Baus y Menéndez Pelayo, debió de enviar también sus Siete tratados a Juan Valera; asi lo hizo saber éste, desde Lisboa, a Menéndez Pelayo en carta fechada el 7 de junio de 188g: “¿Quién es y qué piensa usted del ameri. 
todo su contenido merecerá su aprobación; pero echará U. de creer cuán léjos me hallo de la impiedad y la vana filosofía. Lo que encuentre $\mathrm{U}$. de malo, cúbralo con la indulgencia, que la tolerancia ha sido siempre virtud de varones superiores; y si halla algo que diga con sus propias ideas, redúzcase á esa parte el presente que le hago; pues mi ánimo no es otro que dar á U. una prueba de la consideración y el respeto con que soy de $\mathrm{U}$. atento y seguro servidor.

Hotel de París, Puerta del Sol.

Juan Montalvo

La carta de Montalvo, por más interesada que fuese (y esto lo suponemos, no por el texto, sino por la situación en que fue redactada), desde un principio sentó la oposición ideológica del remitente y el destinatario. Si la cortesía cuidaba de que las divergencias se atenuaran, la sinceridad se defendía ya de la acusadora leyenda ("echará U. de creer cuán lejos me hallo de la impiedad y la vana filosofía"). Menéndez Pelayo dejó sin contestar la carta no por desdén o antipatía, como pudiera suponerse, sino porque prefirió visitarlo personalmente; lo sabemos por su carta de 3 de julio de 1887 ("si le hubiese encontrado en casa cuando le visité en el Hotel de París"). La mala suerte quiso que Montalvo estuviera ausente, de lo cual éste a su vez se lamenta en carta del 17 del mismo mes y año ("siento no haber visto a usted en Madrid cuando me hizo el favor de ir a mi casa"). Luego veremos por qué ambos echaron de menos la entrevista.

La Academia, si llegó a formularse una propuesta oficial, no abrió sus puertas a Montalvo. Es lo único que sabemos, pero sin poder

cano Juan Montalvo? Acabo de recibir carta suya, finísima, y un ejemplar, lujosamente encuadernado, de sus Siete tratados. No he hecho sino hojear esta obra, pero me basta para estimar al autor como eruditísimo y como pensador original y como escritor tal vez sobrado castizo, que peca de rebuscado. Dígame si conoce a Juan Montalvo y qué piensa de él. Ahora está en Madrid" (Epistolario de Valera y Menéndez Pelayo, Madrid, 1946, p. 169). Lástima que no se conserve la contestación de Menéndez Pelayo; pero podemos estar seguros de que en una carta del 15 del mismo mes y año, perdida con otras muchas, no contestó a la pregunta, pues Valera volvió a formulársela el 19 de junio: "¿Quién es Juan Montalvo y qué piensa usted de Juan Montalvo, que me ha enviado un ejemplar de sus Siete tratados, con una carta finísima? Algo de los Siete tratados he leído ya. Del fondo no sé qué pensar aún. De la forma pienso bien. El hombre es original y extraño a veces, pero se conoce que sabe la lengua y nuestros clásicos y mucho de los latinos y griegos. Creo que propende a imitar a Miguel Montaigne" (Epistolario, p. 172). Posiblemente en otra carta desconocida de Menéndez Pelayo, la del 18 de julio de $188_{3}$, fue "manifestada confidencialmente" la respuesta; en su carta a Montalvo de 3 de julio de ${ }_{1887}$, Menéndez Pelayo admitía haber dado tal género de opiniones confidenciales, sin precisar a quién, sobre la "indisciplina intelectual" del ecuatoriano. 
comprobarlo ${ }^{6}$. Los biógrafos y críticos han especulado extensamente sobre la supuesta negativa de la corporación". "Castelar ha afirmado últimamente que cuando tentó el vado halló en los viejos doctos de la calle de Valverde tal tempestad contra el autor de los Siete tratados, que juzgando como ortodojos y no como literatos, le negaban los sacramentos", escribía Montalvo en $\mathbf{1 8 8 7}$. Pero dice, solamente, "tentó el vado"; si así fue, lo más probable es que Castelar, tratando de alcanzarle el nombramiento de miembro correspondiente, sondeara, de palabra, el ánimo de los académicos más destacados, ya que Montalvo no podía conseguirlo por medio de la Academia ecuatoriana, conducto normal, por las enemistades políticas que tenía con sus miembros. Con intentarlo nada se perdía; antes bien, conseguirlo parecía cosa fácil, porque "en ningún tiempo ha dejado la Academia de enviar diplomas de Miembros correspondientes a todas las repúblicas de América, y los sigue prodigando sin resignación ni empacho". La opinión de algunos académicos fue, pues, contraria; no la de la Academia que, al parecer, no fue consultada oficialmente. Montalvo con todo vigor y claridad lo expresó así:

${ }^{6}$ La Academia, no hace mucho, tomó la siguiente determinación: "Con motivo de la petición formulada por un individuo para que se le permita copiar actas de sesiones y correspondencia referente a los Académicos, se toma el acuerdo, para este caso y los sucesivos, de no autorizar el acceso a las Actas y documentos de la Academia hasta que haya transcurrido siglo y medio desde su fecha. Acta de la Comisión Administrativa del 7 de noviembre de 1946". (Cf. la Guia de los Archivos de Madrid, Madrid, 1952, p. 363).

7 Rufino Blanco-Fombona afirma: " $Y Y$ a este grande de España de las letras [Montalvo] no lo quisieron por colega ultramarino, a pesar de Castelar y de Núñez de Arce, las pálidas sombras, cubiertas de orín, de la Academia!" (Introducción a los Siete tratados, ed. Garnier, París, [1912], t. 1, p. xiii). José EnRiQue Rodó, más moderado, dice: “Allí [en Madrid] frecuentó por algún tiempo la sociedad literaria, en la que fue su introductor Emilio Castelar... Leopoldo Alas habló de él con franco homenaje, y don Juan Valera túvole siempre en singular predilección... El triunfo inmediato de su libro [los Siete tratados] no fue, con todo, tan extenso ni intenso como hubiera sido justo esperar... Para privar en ciertos círculos y merecer ciertas sanciones, dañó, sin cluda, a Montalvo, la libre condición de sus ideas, que aún solía ser allí capitis diminutio para los tribunales de la literatura oficial. En suma, de las impresiones de este viaje pareció quedar en el fondo de su espíritu cierto dejo de acritud y desengaño. Volvió a París, donde permaneció hasta su muerte..." (El mirador de Próspero, Montevideo, 1919; ensayo reproducido en Hombres de América, Valencia, 1920, pp. 74-75). Los mismos literatos españoles, por boca de El Sol de Madrid, han escrito lo que sigue: "Montalvo -lo hemos dicho todos muchas veces- es un producto españolísimo que honra y acrecienta nuestro caudal literario, y, sin embargo, la gran decepción del autor de los Siete tratados la motivó un desaire de la Academia Española. A nadie se oculta que hoy nuestra Academia tiene para Montalvo respeto y admiración, porque esa entidad se ha preocupado de exteriorizar tales sentimientos, como una tácita reparación por el deswío de ayer" (citado en $R A, 15,1927$, núm. 19, p. 196). También BlANco-Fomboxa percibe este cambio de actitud cuan- 
"No es verdad, como han propagado mis mal querientes, que yo haya sufrido un rechazo, pues nunca he sido propuesto"s.

No obstante, lastimado por el desdén se retiró sin ruido a París. No devolvió la fallida visita a Menéndez Pelayo ni procuró entrevista con él antes de marcharse (y el hotel de Montalvo estaba situado a poca distancia del Hotel de las Cuatro Naciones, residencia de Menéndez Pelayo). Ni pasados los años olvidó el espíritu gregario de quienes "juzgando como ortodojos y no como literatos, le negaban los sacramentos" a su obra. Varios de ellos llegaron a reconocerle méritos en privado, pero Montalvo no consintió nuevas gestiones para lograr el reconocimiento oficial, dando por seguro que la intolerancia de grupo se lo negaría en público. Suficientemente escarmentado, explicaba a su amigo Julio Calcaño, en octubre de 1887 , los motivos de su actitud:

Según este modo de discurrir de muchos académicos, yo existo fuera de la Academia, y aun soy lo que ellos dicen; pero en la Academia no existo, porque así lo quiere la secta. Los hombres más cuerdos y razonables personalmente, suelen ser egoístas é intratables en corporación, y muchos tienen un voto en el seno de ella, y otro muy diferente fuera de ella9.

Por eso, cuatro años después del infructuoso viaje a Madrid,

do escribe: "Pasaron los tiempos en que se denegaba a don Juan Montaivo el inocente título de académico correspondiente porque don Juan no iba a misa" ("En torno a un incidente", en El Universal Ilustrado, México, año XI, 16 de febrero de 1928, p. 66). Reyes y Guevara, opp. cit., caps. 44 y 38-39 respectivamente, han aprovechado lo novelesco del incidente. ÁnGEL Rosenblat (Introducción a los Capitulos que se le olvidaron a Cervantes, Buenos Aires, 1944, p. 12) y E. Anderson Imbert (El arte de la prosa en Juan Montalyo, México, 1948, pp. 208 y 224) han dado crédito a la "proposición" y el "rechazo" de Montaivo; Anderson Imbert muy lacónicamente los narra así: "No figuró, pues, en la Academia ecuatoriana, pero en $\mathbf{1} 88_{3}$, al visitar España, fue propuesto por Campoamor, Núñez de Arce, Castelar, Valera y la Pardo Bazán a la Academia Española. La Academia rechazó esa gestión" (cap. 1, nota 26). Sin embargo, la prensa diaria madrileña, de ser cierto el episodio, no hizo ningún caso de él: El Progreso, El Globo y La Correspondencia de España, de 5 de junio de $\mathbf{1 8 8 3}$, dieron la noticia de la llegada de Montaivo a la villa y corte con "delicada atención", pero no "como desagravio por el desaire inferido", como presume REYEs, op. cit., p. 385 . El Globo, diario castelariano, anunciaba además una entrevista entre Castelar y Montaivo "en la presente semana", pero que en realidad se verificó el 20, como se sabe por el mismo diario del día siguiente ("Nuestro ilustre jefe, señor Castelar, visitó ayer el Senado, acompañando al notable publicista americano y distinguido amigo nuestro señor Montaivo"). EI único artículo sobre Montaivo y su obra lo publicó también El Globo, 23 de julio de $\mathbf{1 8 8}$, última huella de su permanencia en Madrid. Elogioso, pero con algunos reparos, el autor prefirió no firmarlo.

s Carta de Montaivo a don Julio Calcaño, de "París, octubre 9 de 1887 " (Inéditos y articulos escojidos de Juan Montalvo, Quito, 1897, p. 4).

${ }^{9}$ Ibid., pp. $7^{-8}$. 
no tiene reparo en dirigirse de nuevo a Menéndez Pelayo. Muy a tiempo comprendió Montalvo que la animadversión colectiva poco estorbaría las relaciones estrictamente personales que se disponía a reanudar. En el tono de la próxima carta resulta imposible sorprender el menor resquemor (en el apasionado Montalvo tan pronto a salir a flote). Sincero es el empeño de hallar algún punto común que, por encima de los credos opuestos, fortifique el mutuo respeto intelectual:

Señor don Marcelino Menéndez Pelayo.

París junio 24 de 1887 .

Muy señor mío de todo mi aprecio:

Envío á U. el tomo segundo de mi librito titulado "El Espectador" 10 . Si tiene U. quince minutos de ocio, desperdicíelos en el artículo "El naturalismo", y verá que hasta yo puedo estar acorde con U. en ciertas materias" ${ }^{11}$. Digo esto, porque he visto el prólogo que U. ha puesto á la "Vida de San Francisco" de la señora doña Emilia Pardo, y he tenido mucho gusto de que U. y yo nos hallemos en un corazón respecto de la escuela naturalista de los franceses ${ }^{12}$. Acepte $U$. esta manifestación de los sentimientos de mi ánimo, y créame su más sincero admirador.

Rue Cardinet, 206 ${ }^{13}$.

Juan Montaluo

10 El / Espectador / por / Juan Montalvo. / Tomo segundo.-i5 de junio de 1887. / Paris / Librería Franco-Hispano-Americana, / J. Y. Ferrer, 71, rue de Rennes. 1887 ; $220 \mathrm{pp}$. Con la siguiente dedicatoria autógrafa: "Al Señor don Marcelino Menéndez y Pelayo, con el debido respeto. El autor. París, Junio 24 de 1887 " (signatura $66_{4}$ de la Biblioteca de Menéndez Pelayo).

${ }^{11}$ En "El naturalismo" (cf. El Espectador, t. 2, pp. 92-102) Montalvo exponía su opinión al respecto: "Si el naturalismo es el arte de escribir según la naturaleza y de presentar las costumbres de los hombres y los pasos de la vida como ellos ocurren, yo no alcanzo la necesidad de presentarla siempre por su aspecto desdichado y criminal... El verdadero escritor naturalista seŕ́ el que presente a la naturaleza en todas sus faces. . Nueva doctrina... Sancho Panza es anterior a Emilio Zola, y él puso en la escena de los batanes la piedra del naturalismo. .."

1. Emilia Pardo Bazán, San Francisco de Asis (Siglo xiii). Con un prólogo por D. Marcelino Menéndez y Pelayo, de la Real Academia Española, 2* ed., Garnier, París, 1886. El prólogo de Menéndez Pelayo (pp. ix-xx) entre otras cosas decía: "Es moralmente imposible que la hija de Ozanam pueda ser por largo tiempo y de buena fe, la apologista fervorosa de Zolá y de ios Goncourt. . es imposible que la pluma que trazó los éxtasis del solitario del monte Alvernia y la impresión de los sagrados estigmas, y que acertó a describirlos con verdadera unción, con verdadera piedad, se moje luego en tinta para hacer la apología de los tristes libros que fríamente disecan la fría y senil corrupción parisiense".

${ }^{13}$ Las dos cartas de Montalvo fechadas en París apuntan claramente su domicilio: "Rue Cardinet, 206", no "26", como dice REYes, op. cit., pp. 431 , 435 y $43^{8}$. Blanco-Fombona (loc. cit., p. xlii) y Guevara (op. cit., pp. 199, 
Encontrado el punto de coincidencia literaria, y relacionado con la obra de una común y buena amiga, creyó Montalvo pisar terreno firme. De cierto lo tuvo, tras de aclararse un incidente en sumo grado bochornoso. De poco sirvió que en el mismo tomo de $E l$ Espectador, remitido con dedicatoria, apareciera una "Correspondencia literaria" ("a la señora doña Emilia Pardo Bazán") en la que se refería con elogio a Menéndez Pelayo y se regocijaba de la opinión concorde:

He recibido la nueva edición de la Vida de San Francisco. No me faltaba sino el prólogo de Menéndez y Pelayo, que no contiene la primera. Don Marcelino Menéndez no ha podido dar mejor empleo á su pluma; y pésele a quien le pesare, me alegro mucho de la fraterna que ese gran teólogo pagano les da á ciertas personitas aficionadas al naturalismo de Zola, Goncourt, Flaubert y más hermanos de la cofradía de Le ventre de Paris ${ }^{14}$.

Menéndez Pelayo, al acusar recibo del tomo de El Espectador, en carta de "Madrid, 3 de julio de 1887 ", pasó rápidamente sobre el tema central de la de Montalvo ("convenimos en nuestras apreciaciones acerca del mal llamado naturalismo, capaz de dar náuseas a todo estómago literario y a toda conciencia honrada"), apresurándose a reconocerle, en el volumen recibido y en los Siete tratados, "singulares condiciones de estilo, en medio de una indisciplina intelectual con la que no puedo estar conforme". Juicio no solicitado que le permitió entrar directamente en materia:

Quizá esta opinión mía, manifestada confidencialmente (puesto que en público, ni de Ud. ni de sus libros he tenido nunca ocasión de hablar) me hayan valido de parte de los amigos y admiradores que $\mathrm{Ud}$. tiene en América, diatribas tan feroces y virulentas como una que estampó en La Voz de Panamá, no sé quién, que indudablemente no me conocía ni en lo físico ni en lo moral.

207 y 279) cometen el mismo error; Manuel M. Peralta da otra dirección: "Habitaba [Montalvo] una casa de la rue Logelbach" (citado por Reres, p. 417). Anotemos que en la Rue Cardinet 206 hay una "placa conmemorativa".

${ }_{1 *}$ El Espectador, tomo y ed. cit., p. 211 . Montalvo y doña Emilia asistieron juntos en 1887 a la representación de Le ventre de Paris, drama de Busnach y Zola, primera pieza naturalista que se montó en el Teatro de las $\mathrm{Na}$ ciones (cf. ibid., p. 98); también a la de los "Misterios de Paris que se daba en el Ambigú Cómico" (ibid., p. 96). Manuel M. Peralta, refiriendo otra entrevista de Montalvo y la Pardo Bazán, asegura que "doña Emilia admiraba a Montalvo y tenía por él particular aprecio” (cit. por ReYes, p. 416). Lo cual se confirma en la post-data de la primera carta de Menéndez Pelayo: "Nuestra amiga Da. Emilia Pardo Bazán me ha hablado mucho y muy bien de Ud,"; Montalvo respondió halagado: "Lo que me dice usted de nuestra amiga Doña Emilia, me ha llenado de placer. El que tiene abogados como ése y jueces como usted, ya puede tener acusadores y perseguidores de cualquier linaje". 
Descuidaba Montalvo que las defensas y elogios inmoderados de sus propios admiradores podían utilizarse aviesamente en contra suya; y más, cuando lo publicado envolvía insultos gratuitos para escritores que él mismo leía con admiración y procuraba congraciarse. Si Montalvo hubiera sabido del ataque a Menéndez Pelayo, con toda seguridad habría adelantado explicaciones o guardado silencio; si lo supo y le escribió silenciándolo, no pudo escoger peor momento. Pero Montalvo, en su rápida respuesta de "París, julio 7 de 1887 ", lo negó rotundamente:

Si algún escrito... hubiera yo leído, por cierto que le hubiera ahorrado a usted el disgusto que le ha causado el artículo del periódico a que alude. No conozco este diario; en seis años que permanezco en Francia, nunca me han enviado ni un solo número, ni he tenido noticia de que la prensa de esa ciudad hubiese hecho insultos a usted.

Pero la cosa todavía era más grave: el artículo aludido se imputó al propio Montalvo, no a un simple admirador. En la misma carta, poco más abajo, Menéndez Pelayo vuelve a referirse a "los insultos que contra mí publicó La Voz de Panamá en artículo que atribuye a Ud. el Sr. Pérez y Soto". Afortunadamente no ha dado crédito a semejante atribución:

yo no puedo creer que sea de $\mathrm{Ud}$. porque le conceptúo un perfecto caballero incapaz de apelar a tales recursos contra hombres que en nada le han ofendido, y que a lo sumo pueden haber pecado de alguna negligencia en agradecer sus favores literarios.

Montalvo en su respuesta fue aún más explícito; pasando por alto a "ese señor Pérez y Soto, que usted no conoce, ni yo tampoco", defendió su inocencia con gallardía y entereza, hasta "quedar libre del cargo", no sin mostrarse justamente dolido:

El director de ese periódico podrá certificar si alguna vez ha recibido comunicación mía acerca de ninguna cosa ni persona, y usted dirá si está puesto en razón que paguen justos por pecadores. En cuanto ha que escribo para la imprenta, una sola vez he hecho mención de usted, y ésta, mención honrosa. El que se atribuyan a un escritor artículos anónimos, por pura suposición o por malevolencia, ¿qué ha de probar? Mil veces, periodistas sin fe ni conciencia han citado obras, quizá de ellos mismos, diciendo llanamente: "esto dijo en tal periódico". Puesto que usted mismo no ha dado crédito a esta imputación, no alarguemos un asunto que, por cierto, es tan enojoso para usted como para mí.

Menéndez Pelayo, en su carta de "Santander, 18 de setiembre de 1887 ", aceptó sin restricciones las protestas de lealtad y lo consideró desde entonces como viejo amigo: 
Cuando la causa desaparece, desaparecen también los efectos. Ud. comprenderá que no me faltaban motivos para quejarme de los destemplados y personalisimos ataques que me habían dirigido, sin provocación alguna de mi parte, gentes que se daban por amigas y admiradoras de Ud. Como Ud. ha sido extraño a todo esto, sólo me toca manifestarle mi gratitud por lo sincero y leal de sus explicaciones, que por otra parte yo no necesitaba, puesto que sabía que era Ud. un perfecto caballero. Desaparezca pues, entre nosotros, todo asunto de recriminación, y si en algo puedo servirlo a Ud. mándeme con franqueza como si toda la vida nos hubiéramos conocido.

Si los nublados se aclararon, el origen de la tempestad fue tan oscuro que ni el propio Menéndez Pelayo supo referirlo cabalmente a Montalvo, a pesar de tener a mano buena parte de la documentación precisa. Ni Montalvo, tan cercano a los hechos, llegó a sospecharlo al parecer. Del Ecuador fue remitida a Menéndez Pelayo una voluminosa refutación a los Siete tratados, con firma de Juan Bautista Pérez y Soto, por estos años su detractor más laborioso y enconado ${ }^{15}$. No era la primera vez que Menéndez Pelayo recibía escritos ofensivos contra Montalvo; un académico ecuatoriano, don Pablo Herrera, cumplido corresponsal de Menéndez Pelayo, le envió en $\mathbf{1} 884$ el burlesco "Soneto bilingüe" de García Moreno contra el autor de El Cosmopolita ${ }^{16}$.

Ignoramos quién, con toda intención, remitió los volúmenes (si fue el autor, no se atrevió a dedicarlos); pero no es arriesgado suponer como remitente hasta al más bondadoso de los corresponsales ecuatorianos, adversarios de Montalvo en su mayoría. Menéndez Pelayo conservó en su biblioteca las tres entregas de La curarina, y señaló con su pluma, en los márgenes de la tercera, los insultos contenidos. Quizá ofuscado por la crudeza de la ofensa, no acertó a referir los hechos con rigor. Guiados por las propias señales del ofendido, intentamos reconstruirlos aquí.

En La Estrella de Panamá (no en La Voz, como dice Menéndez. Pelayo) se publicó un artículo "para desacreditar al autor de las Catilinarias y los Siete tratados"; su redactor utilizaba parcialmente

15 La Curarina, / Antidoto contra el montalyismo, / por / Juan Bautista Pérez i Soto. / (Colección de los artículos publicados con este / título en "Los Andes" de Guayaquil. / . . / Guayaquil. / Imprenta de Calvo i Ca. / $188_{1}$ 1886. Las tres entregas de que consta llevan paginación corrida: 1-198. 199382, 383-686 (signaturas 12703,14498 y 14499 de la Biblioteca de Menéndez Pelayo).

${ }^{10}$ Cf. la carta de Herrera a Menéndez Pelayo ("Quito, octubre, " de 1884") publicada en el BBMP, 27 (1951), 228-229. El soneto de García Moreno puede verse en sus Escritos y discursos publicados por la Sociedad Católica de Quito y anotados por su presidente D. Manuel Maria Pólit, Quito, 1887, t. 1. pp. $296-297$. 
los juicios sobre Montalvo aparecidos en Los prosistas contemporáneos en Madrid, del periodista Luis Carreras ${ }^{17}$. Europa y América, quincenario español de París simpatizante de Montalvo, lo refutó en dos artículos anónimos titulados "La conspiración del silencio": citando el mismo libro se ponía en claro que el autor, no obstante considerar oscuro y arcaico el estilo de los Siete tratados, realmente estimaba mucho más a Montalvo que a todos los prosistas contemporáneos, pues sus juicios sobre Castelar, Fernández Guerra, Pi Margall y Menéndez Pelayo no podían ser más depresivos $^{18}$. "La conspiración del silencio", para elogiar a Montalvo, hacía eco hasta cierto punto a los juicios de Carreras (más que juicios, verdaderas injurias y calumnias), pero citaba en todo momento al autor y la obra de donde procedían ${ }^{19}$. Y Juan Bautista Pérez y Soto, empeñado a la sazón en ganar enemigos a los Siete tratados, atribuyó a Montalvo desde las columnas de Los Andes de Guayaquil, con notoria mala fe, no sólo la defensa de Europa y América, sino también las frases de Carreras que allí se citaban"0.

Una duda insalvable: resulta apenas creíble que Montalvo ignorara la verdadera fuente de las injurias. La obra de Carreras que tanto lo distinguía llevaba el pie de imprenta de Europa y América, el mismo de la Mercurial eclesiástica, publicada el año anterior. Aún menos creíble es que desconociera las diatribas de Pérez y Soto, bien conocidas por el redactor de Europa y América ("Justo es que los compatriotas de Montalvo, para honra y gloria de su patria, nos remitan libelos infamantes contra los Siete tratados... como el que... Juan Bautista Pérez y Soto ha tenido la desvergüenza de mandarnos estos días")21. Quizá Montalvo, retirado en París de toda polémica, trataba de apartarse de elogios y diatribas, y prefería acoger el dato erróneo de Menéndez Pelayo para salir del paso sin largas y más enojosas explicaciones. Efectivamente,

17 Luis Carreras [y Lastortas], Los prosistas contemporáneos en Madrid. Estudios sobre el arte de escribir bien, Administración de la Europa y América, París 1885; 185 pp. (las pp. 28, 55-56, 71, 111-126, 151 y $180-181$ se refieren a Montalvo).

${ }_{18}$ No hemos podido consultar los tomos 4 a 6 (1884-1886) de Europa $y$ América, donde se halla "La conspiración del silencio", pero conocemos el texto, transcrito y comentado por Pérez y Soto en la tercera entrega de La curarina, pp. 669-685. En 1883 Europa y América comentó y anunció los Siete tra-

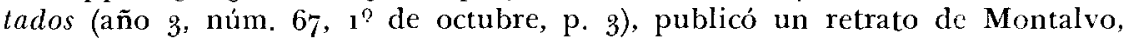
un artículo sobre él, por Eduardo Calcaño, y las cartas de Cantú y D'Amicis (núm. 68, 15 de octubre, pp. 1-2), y el año siguiente editó la Mercurial eclesiástica. Libro de verdades, Biblioteca de Europa y América, París, 1884; $23^{2} \mathrm{pp}$.

${ }_{19}$ La curarina, tercera entrega, pp. $577-579$ y $668-669$.

${ }^{20}$ Ibid., pp. 557 y 668 .

21 Ibid., pp. $68_{4}-68_{5}$. 
sus escritos públicos y privados de estos años parecen despreocuparse de tales acontecimientos: no hacen la menor referencia a Pérez y Soto, ni a Carreras, ni al joven Rubén Darío, que lo defendió de Pérez y Soto y además le dirigió una extensa Epistola en que lo colmaba de elogios ${ }^{22}$. No menos dudoso es que Menéndez Pelayo ignorase Los prosistas contemporáneos en Madrid, que el propio Carreras se encargó de hacer llegar a los ofendidos ${ }^{23}$. Menéndez Pelayo, si recibió el impreso, no puso, y con razón, mayor cuidado en conservarlo. Si en realidad lo llegó a recibir, su reclamo a Montalvo era menos justificado. Pero ellos, a juzgar por lo que sabemos, no dudaron de sus mutuas afirmaciones.

Otro malentendido que surgió a través del epistolario puede ser interpretado con parcialidad; debemos aclararlo aun a riesgo de multiplicar las transcripciones. Unas líneas de la primera carta de Menéndez Pelayo sin duda lastimaron la susceptibilidad patriótica y la honradez literaria de Montalvo, muy a pesar del justo reconomiento que allí mismo se hacía de sus "méritos" como "prosista original":

Ud. con sus ideas que no son las mías, y con procedimientos de polémica que estoy muy lejos de aprobar pero quizá sean tolerables en el Ecuador, es un prosista original, a quien sólo ha faltado vivir en más sana atmósfera. Perdóneme Ud. a mí... el que reconozca y proclame sus méritos, con esta salvedad, que exigen de mí juntamente mi amor a la justicia, y la repugnancia que siempre me ha inspirado toda sátira personal. Muchas de estas cosas yo hubiera tenido el gusto de decírselas a Ud. de palabra, si le hubiese encontrado en casa, cuando le visité en el Hotel de París. Pero mi mala suerte no lo quiso así...

El párrafo que se mutiló al publicar la tercera carta de Montalvo, copiado íntegramente a continuación, puntualiza, en efecto, los conceptos de Menéndez Pelayo:

22 Darío, conocedor de La curarina y admirador de Montalvo, atacó a Pérez y Soto con su artículo "El águila no caza moscas", publicado en El Imparcial, semanario de Managua, año I, núm. 5, 9 de febrero de 1886 (véase en Drego Manuel Sequeira, Rubén Dario criollo, Buenos Aires, 1945, pp. 258-260). La epístola "A Juan Montalvo", fechada en "León de Nicaragua, 1 " de junio de 1884", se publicó en El Ferro-Carril, de Managua, el 20 del mismo mes y año (cf. mi trabajo sobre Los primeros cuentos de Rubén Dario, México, 1951, PP. 47 y 88). Doy más detalles sobre estas relaciones literarias en "Darío y Montalvo", NRFH, 2 (1948), 360-372, y en unos próximos addenda.

El: Elemplar de Los prosistas contemporáneos que se conserva en la B.N.M. (signatura 2/53,771) lleva la siguiente dedicatoria autógrafa: "Remito este ejemplar á D. Francisco Pi Margall pa. qe. se consuele del mal que de él digo en esta obra. Luis Carreras"; abajo, un sello de goma: "Francisco Pi y Margall. Abogado. Madrid”. En la Biblioteca de Menéndez Pelayo (Santander) se encuentran otras obras de Carreras, pero ésta no. 
En el tomo primero de "El Espectador", que se lo envio con gusto, verá usted mi parecer respecto de esa terrible parte de la política y la literatura que se llama polémica; lo leerá en el artículo titulado "El polemista" 24 . Improbar y condenar de una manera absoluta lo que no es de nuestro gusto o nuestro genio, no dirá usted que no envuelve algún abuso de autoridad, aun cuando ésta sea la de todo un Menéndez y Pelayo.

Si tuviera yo grandes motivos de queja contra mi patria, todavía no estaría de acuerdo con los que tienen mala opinión de ella. Un francés que, despechado de la suya, se fue para nunca más volver, volvió dentro de poco, y escribió: "Los defectos y las impertinencias de los pueblos que he visitado y estudiado me han reconciliado con mi patria". Ninguna atmósfera es más sana para el hombre bien nacido que la de su patria. Los defectos, los vicios, las vergüenzas y miserias de los pueblos que he recorrido en quince años de viajes voluntarios o forzados me han reconciliado con la mía; y de acá de estas tierras bajas, mirando hacia la Zona Tórrida con ojos llenos de amor, veo limpia y sana la atmósfera donde respiré el aire de la infancia y aprendí las primeras letras. Si usted alude al abuso de la imprenta, que por desgracia reina en algunas repúblicas de América, los escritos de Enrique Rochefort, de Pablo de Cassagnac, Cornely y otros muchos escritores famosos de todos los partidos en la capital del mundo, son capaces de reconciliarme con el demonio hecho periodista. Y en Londres, la otra capital del mundo, ¿qué ha visto usted, qué hemos visto en estos días? En ninguna república de América, y menos en la mía, hay un Pall Mall Gazette, ni jurados semejantes a los que producen periódicos de esta clase. Sir Charles Dilke, ex-ministro de la Gran Bretaña; Julio Ferry, ministro de la República Francesa, son, sin duda, más desgraciados que yo, porque la atmósfera en que les hacen respirar sus enemigos los envenena. Envenenados por esta atmósfera murieron Leon Gambetta, el general Farre, y están pataleando actual-

${ }^{24} \mathrm{El} /$ Espectador / por / Juan Montalvo / Tomo primero.-1 ${ }^{\circ}$ de junio de 1886. / Paris / Librería Franco-Hispano-Americana, / 78, rue Richelieu; / J. Y. Ferrer, 71, rue de Rennes. / 1886; 219 pp. El ejemplar de la Biblioteca de Menéndez Pelayo (signatura 6363) lleva dedicatoria autógrafa de Montalvo: "Al señor don Marcelino Menéndez y Pelayo, su muy sincero admirador y atento y seguro servidor, Juan Montal uo. París Julio 7 de 1887 ". En "El polemista" (pp. 27-38), artículo que recomienda Montalvo, pueden leerse frases como éstas: "La profesión del polemista es una de las más duras y peligrosas. El polemista es un luchador público...; el vigor, el valor, el tesón que necesita para no sucumbir a los golpes de la elocuencia enemiga, o a los de la infame calumnia, hacen de él un personaje respetable... En el polemista hay siempre pasión; es patriota apasionado, teólogo apasionado, literato apasionado, orador apasionado, filósofo apasionado, llamando pasión ahora al ardimiento con que ciertos caracteres y ciertos corazones se arrojan al torbellino de la contienda política, religiosa o literaria, siempre que en el bando opuesto estén campando paladines dignos de su prepotencia". Confesión personal y manifiesto doctrinario. 
mente los que tienen la desventura de llegar al puerto que les sirve de patíbulo. La atmósfera sana y pura que han menester los pueblos cristianos y cultos, ojalá envolviera toda la tierra. $Y$ no dirá usted que España no está requiriendo una esquinita de ese manto sagrado, para cubrir las carnes de la pobre Merceditas Mar. tín[ez] Campos, verbigracia?

En el tono respetuoso y mesurado no se disimula cierta dosis de acritud; Menéndez Pelayo, en la segunda carta, creyó más oportuno dar nuevo sesgo a la cuestión:

Sólo quiero aclarar un concepto de mi carta que Ud. creyó alusivo a su Patria, y que en mi ánimo no lo era de ningún modo; porque para mí son objetos de especial predilección todos los pueblos que hablan lengua castellana y que constituyen en realidad una sola familia, con los mismos defectos y con las mismas buenas cualidades que distinguen al pueblo español. Lo único que quise decir es que el alejamiento en que ahora vivía Ud. de las luchas y polémicas personales de su país, le iba trayendo, con mucho contentamiento mío, a una manera más alta y serena de mirar las cosas y de juzgar a los hombres. No quise con esto dar a entender (porque esto sería contrario a toda verdad y evidencia) que los desbordamientos de la prensa pública fuesen mayores en América que en Europa. Puntualmente sucede todo lo contrario, pero estos desbordamientos influyen poco en el ánimo de un extranjero, que por el contrario, cuando está en su propio país, aún siendo más limpia y sana la atmósfera, tiene que contagiarse casi involuntariamente del encarnizamiento de las luchas públicas en que toma parte. Nada más que esto quise decir, pues por lo demás ¿quién ha de dudar que un pueblo nuevo, de costumbres sanas y sencillas como el Ecuador, ha de llevar gran ventaja bajo el aspecto moral a esas Babilonias modernas que se llaman París o Londres?

Hemos presentado hasta aquí los aspectos del epistolario que pueden llamarse negativos, resueltos por fortuna amistosamente por los mismos corresponsales. Los aspectos positivos que luego presentamos arrojan un saldo quizá menos rico, pero siempre interesante. Aquí lo literario sale ganancioso, sin menoscabo del aprecio personal que, antes bien, se afirma y fortifica. Establecida la amistad sobre la base del mutuo respeto, no tardó en llegar el libre canje de opiniones y una mayor y recíproca estimación. En la segunda carta de Menéndez Pelayo, otra vez el naturalismo, objeto de común antipatía, proporciona motivos de acuerdo y confidencias literarias:

En las cuestiones relativas a la novela moderna, al naturalismo, ya sabe Ud. que estamos conformes. Pienso como Ud. en cuanto al Héctor Fieramosca de Massimo de Azeglio, aunque todavía prefiero otra novela suya intitulada, si mal no recuerdo, Niccolo de 
$L a p i$, y cuyo asunto es el asedio de Florencia en ${ }_{15}^{27}$. En cuanto a $I$ promessi sposi, no sólo los admiro sino que los amo con cierta especie de devoción íntima. Son la segunda novela del mundo después del Quixote. A lo menos, yo no conozco otra mejor ${ }^{25}$.

Quien hasta hace poco se declaraba abiertamente inconforme con la "indisciplina intelectual" del presunto enemigo, ahora prefiere la intimidad en voz baja y la comunicación efusiva de sus preferencias más íntimas. Los reparos ideológicos pasan a ocupar un segundo plano, y los que se hacen al estilo son tan sinceros y evidentes que ni al más puntilloso habrían podido ofender. $Y$ todo ello envuelto en halagüeños adjetivos, dictados igualmente por la cordialidad y el reconocimiento:

...el primer tomo de El Espectador... me ha hecho pasar, lo mismo que el segundo, ratos muy agradables, trayéndome a la memoria los mejores artículos de Addison o los de Gaspar Gozzi en su Osservatore, que me gusta todavía más que el Spectator inglés ${ }^{26}$. Ud., procediendo con entera originalidad, ha logrado, no obstante, parecerse a estos amables moralistas y a veces al mismo Montaigne, sin que se trasluzca imitación directa. Claro que no

¿5 En "La novela francesa y la italiana", Montalvo se refiere a Massimo Tapparelli d'Azeglio (1798-1866) y a su Eltore Fieramosca (1833), olvidándose del Niccoló de' Lapi (1841), preferido por Menéndez Pelayo (El Espectador, libro segundo, ed. Garnier, París, 1927, pp. 169-178); a Manzoni y sus Promessi sposi (1827) dedica especial atención: "Los desposados -opina-son una de las obras que, en forma de novela, han sido más vigorosamente concebidas y más admirablemente puestas por escrito en nuestros tiempos" (ibid., pp. 167-168). Cabe señalar la moderación (y modernidad) del juicio de Montalvo, sobre todo si se lo compara con el de Menéndez Pelayo, invariable en este punto por lo menos desde hacía doce años, y siempre tendiente a situar la novela de Manzoni al lado del Quijote, admirativamente. El manuscrito de su tesis doctoral sobre La novela entre los latinos (1875) finaliza con este párrafo, muy diferente del impreso en su folleto del mismo título y del mismo año: “...el Quijote, encarnación bellísima de la idea del Renacimiento, I promessi sposi, pintura sin igual de los pasados tiempos, animada por el espíritu de la edad presente!" (cf. A. Bonilla y San Martín, Introducción al t. 4 de los Origenes de la novela, ed. $N B A E$, p. 97). Exaltaciones parecidas se encuentran en la carta a José María de Pereda ("Venecia-Milán, 13 de mayo de 1877 "), ahora en el t. 5 de los Estudios y discursos de critica histórica y literaria, ed. de obras

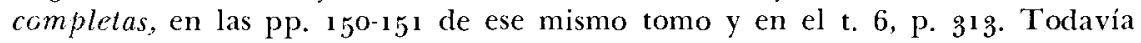
en $189^{\circ}$ sigue fiel a Manzoni, aunque no sabemos si con la misma pasión: "Por entonces dio en Madrid una conferencia pública acerca de Manzoni; pero fue casi totalmente hablada, y no había taquígrafos, por lo cual resultó imposible recogerla" (Bonilla y SAN Martín, loc. cit., p. 51). Otras rectificaciones o "palinodias" a sus juicios juveniles hizo don Marcelino, pero no ésta.

$\because$ Joseph Addison (1672+1719) y su Spectator (1711-1712 y 1714) y Gasparo Gozi $\left(1713^{-1786)}\right.$ y su Osservatore Veneto (1761-1768). El mismo juicio de Menéndez Pelayo sobre Addison y Gozzi puede verse en los Esludios y discursos de critica histórica y literaria, ed. cit., t. 5, p. 345. 
son de mi agrado todas las ideas expuestas en El Espectador, pero aun en esto noto mayor templanza y serenidad que en los Siete tratados, así como también indudable ventaja en el estilo, que es más suelto y fácil en estos nuevos artículos, notándose en ellos menos rebusco de arcaísmos artificiosos. Digo a Ud. con toda franqueza y sinceridad mi impresión. Y no quiero disimular tampoco que siendo en general pura, castiza y abundante la dicción de Ud., la afean de vez en cuando algunos galicismos inútiles y por otra parte desconocidos en España, como el de romancista por novelista y romance por novela. En España nadie entiende por romance otra cosa que la composición poética en versos octosílabos asonantados. Por eso creo que además de ser inútil este galicismo, tiene el inconveniente de ser anfibológico, y de confundir al que lee ${ }^{2 \tau}$. Claro es que este lunar es de poca nota, pero como se trata de un estilo, en general tan atildado y cuyo ideal es la pureza clásica, me atrevo a notarle, pidiendo a Ud. mil perdones por tal atrevimiento.

No sabemos si Montalvo contestó la última carta de Menéndez Pelayo; parece más probable que no llegó a contestarla. Seguramente pensaría hacerlo cuando le remitiera el volumen tercero de El Espectador, entonces en prensa; pero la enfermedad que lo llevó a la tumba impidió uno y otro propósito. Montalvo ocupó los últimos meses de 1887 y los primeros de 1888 en cuidar la edición de ese volumen. "Durante seis meses a partir de marzo, mes en que se diera [sic] término a la impresión del número tercero de El Espectador, no pudo salir a la calle ni escribir una letra"; pescó un lamentable resfrío cuando ya corregía pruebas de los pliegos fina$\operatorname{les}^{28}$. En estos pliegos, precisamente, Montalvo publicaba su mea culpa de galicista: citando de memoria la carta de Menéndez Pelayo, aceptaba la corrección con humildad y beneplácito. Satisfecho de lo justo y benigno de la censura, y orgulloso de la amistad con el sabio crítico que se ocupaba de su obra, redacta la confesión de su yerro visiblemente regocijado:

\section{PRO LINGUA ${ }^{29}$}

Me gusta la vigilancia con que algunos literatos montan la guardia en el palacio del idioma; y cuando uno de estos vigías de penetrante vista nos advierte la presencia del enemigo, soy el primero en echar el arma al brazo e ir en defensa de esta segunda religión que se llama lengua pura, lengua clásica. Don Marcelino Menéndez y Pelayo me ha dado la voz de: Moros en la costa: y aquí me tienen ustedes lanza en ristre contra ese musulmán lla-

${ }_{27}$ Véase "La novela francesa y Ia italiana", loc. cit., pp. 159-161.

${ }_{28}$ REYES, op. cit., pp. 428-430.

29 "Pro lingua" es el último artículo del t. 3 de El Espectador, aparecido en París el 15 de marzo de 1888 (cf. ed. Garnier, 1927, pp. 312-313). 
mado El Espectador, que nos ha traído envuelto en su manto de rey antiguo un moro Muza desemejable, que puede hacer daño, si no en España, por lo menos en América... "Romance, dice don Marcelino, es galicismo en la significación de novela. En España nadie comprende que se habla de novela cuando se la llama romance". Como si no hubiera sabido esto, fui yo a soltar ese gazapo en el tomo segundo de El Espectador ${ }^{30}$. Romance, en español, es la composición en verso de arte menor, en donde se refieren amores, aventuras o hechos de armas de los héroes populares. El $R o$ mancero del Cid hubiera bastado para salvarme de ese error, si, por mucha que sea nuestra buena voluntad, no nos faltaran la atención y advertencia cuando más necesitamos de ellas. Entre franceses romance es la verdadera novela; y nouvelles llaman éstos a las novelillas cortas. Le pongo, pues, de patitas en la calle a ese gabacho advenedizo, y los dominios del Espectador quedan libres de moros, francos y lombardos, gracias a don Marcelino Menéndez.

Sin embargo, la concordia a que llegaron las relaciones no obligaba a la renuncia de los credos respectivos ni excluía la posibilidad de su manifestación antagónica. No de otra manera se explica el recelo que Montalvo, en esos mismos días, manifiesta ante el probable voto académico de Menéndez Pelayo; a un tiempo escribía Montalvo el jovial artículo de El Espectador y el siguiente párrafo de la carta a Calcaño ("París, octubre 9 de 1887"):

Confieso que, sin ser soberbio, yo no solicitara [el ingreso a la Academia] ni una vez, menos cuatro; y tanto menos cuanto que estoy cierto de que don Marcelino Menéndez y Pelayo, que me ha honrado con sus cartas como á escritor; don Aureliano Fernández Guerra, que "por dondequiera que abra ese maldito libro [los Siete tratados] halla un pasaje elocuentísimo"; don Manuel Tamayo y Baus, que se admira de que yo no esté en la Academia; y otros muchos respetables varones me echarian bola negra, si Castelar, Núñez de Arce ú otro de los miembros de buenas ideas, como decimos los liberales, viniese a proponerme ${ }^{31}$.

Por otra parte, la prevención de Montalvo se dirige al Menéndez Pelayo académico, no al amigo particular; en la misma carta, un poco antes, se duele de aquellos "hombres más cuerdos y razonables personalmente" que "suelen ser egoístas é intratables en corporación, y muchos tienen un voto en el seno de ella, y otro muy diferente fuera de ella" ${ }^{32}$. La alusión no puede ser más directa.

${ }^{30}$ Cf. supra, nota 27 . La disculpa de Montalvo no se extiende a romancista 'novelista', usado por él al mismo tiempo que romance 'novela'.

${ }^{31}$ La carta a Calcaño fue de las últimas que pudo escribir Montalvo; con toda seguridad ya había recibido la segunda de Menéndez Pelayo ("Santander, 18 de setiembre de 1887 "), lo que justifica el plural cartas (cf. supra, nota 8).

${ }^{32}$ Inéditos y artículos escojidos de Juan Montalvo, ed. cit., pp. 7-8. 
Una prueba de que Montalvo no andaba muy alejado de la verdad al imaginarse el criterio académico de Menéndez Pelayo, la proporciona una carta de éste a don Gumersindo Laverde Ruiz (7 de octubre de 1885), escrita solamente dos años después de la visita de Montalvo a Madrid y dos años antes de la carta a don Julio Calcaño:

He oido decir que, para la vacante de la Academia española, se piensa en Ceferino Suárez Bravo. Lo merece por todos conceptos; pero (ací para entre nosotros) creo que debíamos abusar menos de la ventaja del número, y dar entrada de vez en cuando a algún liberal inofensivo y de mérito, o a algún escritor de relumbrón que nos congraciara un tanto con las masas. Van tres neos seguidos, y parece demasiada intolerancia. Yo no tendría inconveniente en votar a Galdós por ejemplo; pero Tamayo, Cañete y Aureliano piensan de otra manera, y van cerrando demasiado el círculo. De todas maneras, mientras tengamos verdaderos literatos, como Suárez Bravo, los daños de este exclusivismo no serán grandes".

Montalvo comprendía muy bien que los "egoístas e intratables en corporación" podían ser a veces "cuerdos y razonables personalmente", sobre todo Menéndez Pelayo, que ya parecía haber olvidado hasta el mismo voto contrario de Castelar cuando su elección académica:34, y que con ánimo más transigente no negaba ahora "a algún liberal inofensivo y de mérito" la entrada en la Academia. Actitudes aparentemente tan opuestas proceden de las más profundas convicciones de ambos escritores: creían posible mantener la concordia privada sin ocultar sus personales ideologías.

Que Montalvo no era el "liberal" que Menéndez Pelayo habría estado dispuesto a admitir públicamente en la Academia, lo podemos inferir de la prioridad que daba a lo "inofensivo" del posible candidato, posponiendo sus intrínsecos méritos. Fuera de toda duda, Montalvo no fue nunca, ni aun muerto, el "liberal inofensivo" que los prejuicios de Menéndez Pelayo podían soportar, por más méritos literarios que éste, privadamente, le concediera. El juicio definitivo de Menéndez Pelayo demuestra igual prevención; apareció a los cinco años escasos de la muerte de Montalvo en la Antología de poetas hispano-americanos, en una nota de pie de página sobre los parnasos y antologías del Ecuador publicados y proyectados hasta la fecha:

Falta a esta Antologia [ecuatoriana $]^{3 \pi}$ un tercer tomo de pro. sistas que está confiado a la docta dirección de D. Pablo Herrera

$\because$ Bonilla y Sax Martín, loc. cit., p. $4^{6}$.

"En diciembre de 1880 don Marcelino fue electo académico con el roto adverso de Emilio Castelar (cf. Bonilla, p. 42).

s5 La Antologia ecuatoriana publicada en Quito en 1892; el primer tomo 
y será quizá el más interesante, porque la aguadísima vida política del Ecuador ha hecho que el ingenio de sus hijos brille y se desarrolle principalmente en el campo de la polémica social y religiosa. Los nombres de Espejo, Mejía, el P. Solano, García Moreno y otros, a los cuales conviene añadir ya, con las necesarias reservas de ortodoxia y de gusto, el del sofista agudo e ingeniosísimo, y brillante y castizo, aunque abigarrado y algo pedantesco prosista, Juan Montalvo, pueden dar especial interés a esta sección $^{36}$.

En verdad, no hacía falta esta extensa nota sobre una antología de prosa, todavía en proyecto, en una antología de poesía; pero Menéndez Pelayo quiso de una vez, aprovechando la ocasión, manifestar -y quizá imponer- su opinión sobre Montalvo a los amigos conservadores del Ecuador, en especial a su viejo corresponsal don Pablo Herrera. La intención de Menéndez Pelayo era, si no generosa, justa: no quería contribuir con el silencio a la exclusión de Montalvo, no ya posible sino segura si él no la evitaba. Por el contrario, la más leve indicación ("conviene añadir ya") serviría de orden expresa a sus admiradores ecuatorianos.

Pero su propósito fue redactado, como hemos visto, de la manera más curiosa. Podría asegurarse que el texto manuscrito está lleno de borrones y tachaduras; no se puede escribir con limpieza de un solo intento la luenga y entrecortada frase final. De los cuatro adjetivos meritorios ("agudo e ingeniosísimo, y brillante y castizo"), los dos primeros se refieren al "sofista", y los dos últimos al "prosista", pero se atenúan rápidamente con otros dos, bien negativos ("abigarrado" y "pedantesco"). Las mismas conjunciones, cargadas de suspenso, evidencian la momentánea indecisión del espíritu, la inseguridad de la mano. Sin embargo, pocas veces don Marcelino habló tan claro; las "necesarias reservas" que juzga preciso tener con Montalvo, son primeramente "de ortodoxia", y, luego, "de gusto”. Las primeras van dirigidas al sofista, a los ojos de Menéndez Pelayo más de tomarse en cuenta por lo "agudo e ingeniosísimo", que el prosista "abigarrado y algo pedantesco", por más "brillante y castizo" que fuese. "De ortodoxia y de gusto", "liberal inofensivo y de mérito", son frases de íntimo paralelismo mental. Primero la

reúne solamente a los Poetas, y el segundo, los Cantares del pueblo ecuatoriano, compilación formada por Juan León Mera. Otros dos tomos, dedicados a los Prosistas, aparecerian más tarde.

: Antologia de poetas hispano-americanos, t. 9, Madrid, I894, p. cxlvii, noti. Ya Alfonso Reyes, en 1919, había llamado la atención sobre esta nota: "Menéndez y Pelayo habla de él [de Montalvo] con unas reservas que son de por si harto elocuentes", dice, y a continuación subraya en el texto "añadir ya" y "nunque abigarrado" (Simpatias y diferencias, Primera serie, Madrid, 1921, 13. I74: en las Obras completas, t. 4, México, 1956, p. 79, advierte: "Las itáliats son mías"). 
creencia; después la estética. Pero Montalvo nunca ignoró que había quienes juzgaban "como ortodojos y no como literatos".

La ortodoxia fue aún más lejos en el juicio de Menéndez Pelayo; la prevenida y reticente nota sobre Montalvo contrasta violentamente con la apología de García Moreno que figura en la siguiente página. Tras recitar los lugares comunes que prefieren los partidarios más fervorosos, llega a reconocerle "grandes dotes para la alta poesía satírica", en las mismas composiciones donde el ojo crítico descubría "los descuidos inherentes a todo lo que se escribe para no ser impreso" 37. Y Menéndez Pelayo ya conocía los dos volúmenes de Escritos y discursos (Quito, Imprenta del Clero, 1887-1888), en uno de los cuales aparece el "Soneto bilingüe" contra Montalvo que don Pablo Herrera le había enviado manuscrito desde 1884 (cf. supra, nota 16).

Años después, ya para morir en 1912, volvió Menéndez Pelayo a leer las páginas de su reseña histórica sobre la poesía en el Ecuador; al entregar a Victoriano Suárez los prólogos de la Antología para formar la Historia de la poesia hispano-americana, hizo algunas enmiendas y adiciones. La pluma autocrítica pasó en alto sobre el juicio referente a Montalvo. Todavía se detuvo en el renglón anterior para hacer una adición; la hizo. Lo que seguía estaba correcto.

La adición no tuvo más oficio que el de señalar la relectura de Menéndez Pelayo y la inmovilidad de su juicio sobre Montalvo. Ese renglón añadido a la nota sobre el futuro tomo de prosistas de la Antologia ecuatoriana ("No tengo noticia de que este tomo se haya publicado") no hacía falta, como tampoco la nota mismasi. Por otra parte, la prodigiosa memoria, seguramente ya fatigada, no estaba en lo cierto. Desde el 8 de julio de 1893 don Pablo Herrera le daba cuenta de su impresión ("Nuestra Antología de prosistas ecuatorianos va avanzando; saldrá en dos o tres tomos, y el primero estará concluido dentro de pocos días"), y aunque ésta se retrasó en dos años, el tomo primero por lo menos fue remitido puntualmente a Menéndez Pelayo ${ }^{39}$. En el prólogo de Herrera se cita un elogio de Espejo procedente de la Antologia de poetas hispano-americanos; no parece probable que Menéndez Pelayo haya omitido su examen: el ejemplar enviado fue abierto a su tiempo y todavía se conserva en su Biblioteca ${ }^{40}$. Con toda seguridad, Menéndez Pelayo no habría olvidado el primer volumen de la Antologia de prosistas

${ }^{87}$ Antología de poetas hispano-americanos, loc. cit., p. cxlviii.

${ }^{38}$ Historia de la poesía hispano-americana, Madrid, 1919, t. 2, p. 133, nota.

${ }^{89}$ La carta de Herrera puede verse también en el $B B M P, 27$, pp. 237-238.

${ }^{40}$ Antología de prosistas ecuatorianos, Imprenta del Gobierno, Quito, 1895 , I; $417 \mathrm{pp}$. La cita de Menéndez Pelayo aparece en la p. xliv del Prólogo, y procede de la Antologia de poetas hispano-americanos, p. civ. 
ecuatorianos si en éste hubiera figurado Montalvo. $\mathrm{Y}$ el segundo, que debía incluirlo por la simple cronología, lo eliminó, contrariando el deseo de Menéndez Pelayo ${ }^{41}$. Quizá por eso no le fue remitido. Ya que el primero para él no contaba, mantuvo hasta el fin el criterio de incluir a Montalvo, "con las necesarias reservas de ortodoxia y de gusto", creyendo que la Antología estaba aún en proyecto.

Así concluyen las relaciones literarias y personales de estos dos hombres representativos de su cultura en el fin de siglo. La tradición española y el liberalismo americano se enfrentaron, quizá por última vez, con igual tenacidad y grandeza. Generosidad e intransigencia parecen ser comunes a ambos. Ni la caridad cristiana ni la concordia más humanista explican por sí solas este modo de relaciones: respeto del credo ajeno, búsqueda de puntos comunes, condescendencia, casi galantería con el adversario; en suma, liberal tolerancia y franco apostolado. El "estúpido siglo xix" creyó en la tolerancia y la persuasión como en virtudes propias del hombre. Los tiempos que corren nos hacen añorar ese candor. El liberalismo se nos presenta a los ojos de hoy como fruto de otra edad "enorme y delicada".

El Colegio de México.

Ernesto Mejía Sánchez

${ }^{41}$ Antología de prosistas ecuatorianos, Imprenta del Gobierno, Quito, 1896 , II; $3^{\circ}$ I pp. No hemos podido consultar personalmente este volumen, pero el doctor Manuel Alcalá, director de la Biblioteca Nacional de México, consultó a don Joaquín Ruales Laso, director de la Biblioteca Nacional de Quito, quien le contestó lo que sigue el 18 de septiembre de 1957 : "ni en el prólogo ni en ninguno de los dos volúmenes, hace Herrera mención alguna de Juan Montalvo". 